\title{
Underglycosylated prion protein modulates plaque formation in the brain
}

\author{
Jason C. Bartz \\ Department of Medical Microbiology and Immunology, School of Medicine, Creighton University, Omaha, Nebraska, USA.
}

\begin{abstract}
The prion agent is unique in biology and is comprised of prion protein scrapie (PrPsc), a self-templating conformational variant of the host encoded prion protein cellular (PrPC). The deposition patterns of PrPsc in the CNS can vary considerably from a diffuse synaptic pattern to large plaque-like aggregates. Alterations of $\mathrm{PrP}^{\complement}$ posttranslational processing can change PrP ${ }^{\mathrm{sc}}$ deposition patterns; however, the mechanism underlying these observations is unclear. In this issue of the $J C l$, Sevillano and authors determined that parenchymal PrPsc plaques of the mouse brain preferentially incorporated underglycosylated $\mathrm{PrP}^{\mathrm{C}}$ that had been liberated from the cell surface by the metalloproteinase, ADAM-10, in combination with heparan sulfate. These results provide mechanistic insight into the formation of $\mathrm{PrP}^{\mathrm{sc}}$ plaques and suggest that PrP posttranslational modifications direct pathogenicity as well as the rate of disease progression.
\end{abstract}

\section{Protein-only infectious agents}

Prions are protein-only infectious agents that subvert the normal form of the host cellular prion protein, $\operatorname{PrP}^{\mathrm{C}}$, to the self-templating scrapie prion form, $\operatorname{PrP}^{\mathrm{Sc}}$ $(1,2)$. Due to the unique nature of prions, the properties of both the host $\mathrm{PrP}^{\mathrm{C}}$ and agent $\mathrm{PrP}^{\mathrm{Sc}}$ contribute to the pathogenesis of disease. Specifically, strains of prions result in distinct patterns of $\mathrm{PrP}^{\mathrm{Sc}}$ deposition and neurodegeneration in the CNS that are encoded by strainspecific conformations of $\operatorname{PrP}^{\mathrm{Sc}}(3,4)$. Interestingly, changes in the host $\operatorname{PrP}^{\mathrm{C}}$ can result in alteration of the phenotype of disease, including neuropathology, in the absence of altering the prion strain. For example, murine $\mathrm{PrP}^{\mathrm{C}}$ is polymorphic with two alleles, and inoculation of $\mathrm{ME} 7$ from one $\mathrm{PrP}^{\mathrm{C}}$ genetic background to the other resulted in a change in both the incubation period of disease and the distribution of neurodegeneration (5). Importantly, back passage of ME7 to the original $\mathrm{PrP}^{\mathrm{C}}$ genetic background resulted in an incubation period and neuropathology indistinguishable from the original $\operatorname{PrP}^{\mathrm{C}}$ allele (i.e., class 1 strain) (5). This seminal work indicated that differences in the amino acid sequence of $\operatorname{PrP}^{\mathrm{C}}$ contribute to the pathogenesis of disease independently of the prion strain.

\section{Altering prion pathogenesis}

Posttranslational modifications of $\operatorname{PrP}^{\mathrm{C}}$ can alter prion pathogenesis. $\operatorname{PrP}^{\mathrm{C}}$ is tethered to the cell membrane by a glycophosphatidylinositol (GPI) anchor (6). In transgenic mice, deleting the $\mathrm{PrP}^{\mathrm{C}}$ GPI anchor results in $\operatorname{PrP}^{\mathrm{C}}$ retrafficking into the intracellular space. Subsequent prion inoculation resulted in $\mathrm{PrP}^{\mathrm{Sc}}$ formation, indicating that prion conversion is independent of the GPI anchor (7). Importantly, these mice showed substantial $\mathrm{PrP}^{\mathrm{Sc}}$ distribution differences in the whole body as well as differences in the CNS. In the CNS, the pattern of $\mathrm{PrP}^{\mathrm{Sc}}$ deposition was characterized by dense plaque-like formations, compared with
Related Article: p. 1350

Conflict of interest: The author has declared that no conflict of interest exists.

Copyright: $\odot 2020$, American Society for Clinical Investigation.

Reference information: / Clin Invest. 2020;130(3):1087-1089. https://doi.org/10.1172/JCI134842. the more diffuse synaptic pattern of $\mathrm{PrP}^{\mathrm{Sc}}$ deposition in nontransgenic WT animals. While prion infection of $\operatorname{PrP}^{\mathrm{C}}$ GPI anchorless mice resulted in prion formation, these animals did not develop clinical signs of prion disease. It is unclear if their healthy phenotype is due to a failure of $\mathrm{PrP}^{\mathrm{sc}}$ to gain access to the areas of the CNS responsible for the onset of clinical signs, if the $\mathrm{PrP}^{\mathrm{Sc}}$ generated was less neurotoxic, or if the absence of symptoms was a property of the strain tested.

In addition to a GPI anchor, $\operatorname{PrP}^{\mathrm{C}}$ contains two N-linked glycosylation sites that have variable occupancy $(8,9)$. Transgenic mice in which the $\mathrm{PrP}^{\mathrm{C}}$ lacked both $\mathrm{N}$-linked glycosylation sites still supported prion formation. $\mathrm{PrP}^{\mathrm{Sc}}$ from these mice transmits prion disease to WT mice, indicating that glycosylation is not required for prion formation or transmission (10). In the strains tested, however, the absence of $\mathrm{PrP}^{\mathrm{C}}$ glycosylation resulted in an increase in incubation period and $\operatorname{PrP}^{\mathrm{Sc}}$ amyloid plaque deposits compared with WT animals that have a full repertoire of $\operatorname{PrP}^{\mathrm{C}}$ glycosylation. Shifting of $\operatorname{PrP}^{\mathrm{Sc}}$ to a more amyloid plaque structure can reduce the pathogenicity of $\mathrm{PrP}^{\mathrm{Sc}}$ by extraneuronal routes of infection, consistent with the hypothesis that small, soluble $\mathrm{PrP}^{\mathrm{sc}}$ oligomers are the preferred species of $\mathrm{PrP}^{\mathrm{Sc}}$ for retrograde transport in the peripheral nervous system that facilitates neuroinvasion $(11,12)$. Both GPI anchorless $\mathrm{PrP}^{\mathrm{C}}$ and underglycosylated $\mathrm{PrP}^{\mathrm{C}}$ share a common neuropathological feature of parenchymal $\mathrm{PrP}^{\mathrm{Sc}}$ plaques. These studies indicate that alteration of $\operatorname{PrP}^{\mathrm{C}}$ posttranslational modifications can result in profound changes in the neuropathology of prion disease. The mechanism responsible for these observations is, however, unclear.

\section{How PrPc posttranslational modifications may alter neuropathology}

The work of Sevillano et al. in this issue of the JCI examines the mechanism of how $\operatorname{PrP}^{\mathrm{C}}$ posttranslational modifications alter 


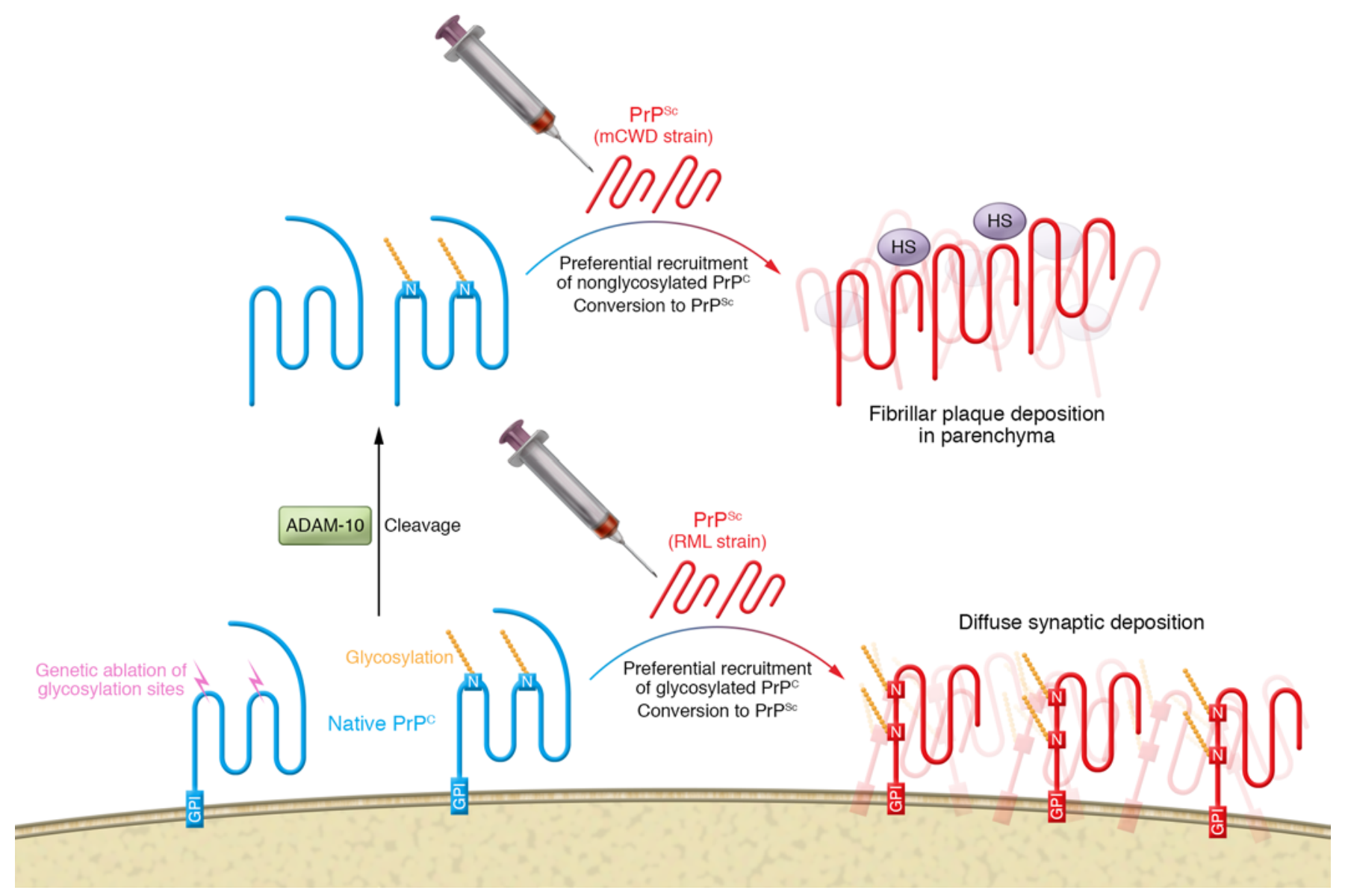

Figure 1. Role of posttranslational processing of PrPc in the formation of prion aggregates. Fibrillar prion strains such as mCWD preferentially incorporate underglycosylated $\mathrm{PrP}^{\mathrm{C}}$ (blue) that is released from the cell surface by ADAM-10 into plaques that form in association with HS in the parenchyma. Subfibrillar prion stains, such as RML, preferentially incorporate glycosylated PrPC into diffuse synaptic deposits of PrP ${ }^{\text {Sc }}$ (red) without a HS scaffold. Genetic ablation of $\mathrm{N}$-linked glycosylation sites $(\mathrm{N})$ can switch in nonfibrillar strain pathology from synaptic diffuse deposition to plaque-like deposition of PrPsc in the parenchyma.

neuropathology (13). Mice expressing unglycosylated $\operatorname{PrP}^{\mathrm{C}}$ were generated $\left(\operatorname{Prnp}^{180 \mathrm{Q} / 1960}\right.$ ) and were shown to have normal $\mathrm{PrP}^{\mathrm{C}}$ expression patterns that, importantly, failed to spontaneously develop neurodegeneration. The Prnp ${ }^{180 Q / 196 Q}$ mice were challenged with four murine-adapted prion strains, three of which (RML, 22L, and ME7) are categorized as subfibrillar strains with a predominately diffuse synaptic pattern of $\mathrm{PrP}^{\mathrm{Sc}}$ deposition in the CNS, and one of which (mCWD) is a fibrillar strain that is characterized by large plaques of $\mathrm{PrP}^{\mathrm{sc}}$ in the $\mathrm{CNS}$. All of the strains tested resulted in the $\operatorname{Pr}^{1800 / 196 Q}$ animals developing prion disease. Notably, the mice inoculated with the subfibrillar strains developed plaque-like deposits. This altered neuropathology is consistent with previous studies indicating that reduced $\operatorname{PrP}^{\mathrm{C}}$ glycosylation results in an increase in $\mathrm{PrP}^{\mathrm{sc}}$ plaque formation (10). To examine the composition of these plaque-like deposits in the Prnp ${ }^{180 Q / 196 Q}$ mice, the authors used an anti-
PrPantibody that specifically recognizes PrP that has been cleaved from the cell surface by the metalloproteinase ADAM-10 (14). It was determined that the $\mathrm{PrP}^{\mathrm{sc}}$ plaques were enriched for ADAM-10-cleaved PrP. Next, the authors identified that heparan sulfate (HS) colocalized to the plaques but was restricted from areas with diffuse aggregates of $\mathrm{PrP}^{\mathrm{Sc}}$. Consistently, HS specifically bound to PrP that had been cleaved by ADAM-10. Further, the HS/ADAM-10-cleaved PrP interaction was influenced by the glycosylation state of $\mathrm{PrP}$ where a progressive reduction in the glycosylation of PrP resulted in a corresponding increase in affinity of $\operatorname{PrP}$ to bind HS. These data suggest that underglycosylated $\mathrm{PrP}^{\mathrm{C}}$ that is cleaved from the cell surface in combination with HS produces large plaque-like structures.

To test the hypothesis that glycosylation influences plaque-like pathology, Sevillano and colleagues generated novel transgenic mice that expressed $\operatorname{PrP}^{\mathrm{C}}$ with three N-linked glycosylation sites (Prn $\left.p^{187 N}\right)$ (13). Inoculation of the Prnp $p^{187 N}$ mice with the plaque-forming strain $\mathrm{mCWD}$ resulted in a neuropathology that lacked plaques and instead was comprised of diffuse $\mathrm{PrP}^{\mathrm{Sc}}$ deposits compared with WT mice that contain $2 \mathrm{~N}$-linked $\operatorname{PrP}^{\mathrm{C}}$ glycosylation sites. This observation is consistent with the premise that $\operatorname{PrP}$ glycosylation inhibits $\mathrm{PrP}^{\mathrm{Sc}}$ fibril formation by interfering with binding to HS. Overall, a model for prion formation suggests that underglycosylated PrP released from the cell surface associates with HS to form large parenchymal deposits, whereas cell-bound fully glycosylated $\mathrm{PrP}^{\mathrm{Sc}}$ preferentially forms small diffuse aggregates (Figure 1 and ref. 13).

The role of the prion strain in the preponderance to form plaques versus diffuse deposits of $\operatorname{PrP}^{\mathrm{Sc}}$ is only partially understood. Transmission of all four prion strains to $\operatorname{Prn} p^{180 Q / 196 Q}$ mice resulted in an increase in plaque-like $\operatorname{PrP}^{\mathrm{sc}}$ deposits in the CNS. 
However, the degree to which plaquelike deposits increased was not uniform between the strains tested. The mechanism behind this observation remains unclear (13). It is possible that the strain-specific differences in the preferred $\operatorname{PrP}^{\mathrm{C}}$ substrate for conversion, as has been identified using in vitro studies, may play a role in this observation (15). In addition, strain-specific rates of formation and clearance may favor specific patterns of prion accumulation (16).

\section{Changing the incubation period of prion disease}

Strain-specific responses in the alteration of the incubation period of disease in the Prnp ${ }^{1800 / 1960}$ mice were observed. Specifically, the incubation period of RMLinfected WT or Prnp ${ }^{180 Q / 196 Q}$ mice was similar. This was in contrast to that of $22 \mathrm{~L}-$ infected animals, where the incubation period of Prnp ${ }^{180 Q / 196 Q-i n f e c t e d ~ m i c e ~ w a s ~ l o n g e r ~}$ compared with WT mice. Importantly, the extended incubation period of RML-infected Prnp $p^{180 Q / 196 Q}$ mice was preserved upon second passage. One potential explanation for this observation is that differences in the PrP amino acid sequence between the WT and Prnp ${ }^{180 Q / 196 Q}$ mice may cause a species barrier-like phenomenon that can alter strain properties. Alternatively, while evidence suggests that glycosylation is not required on the inoculum $\operatorname{PrP}^{\mathrm{Sc}}$ to maintain strain properties (17), it is possible the host $\operatorname{PrP}^{\mathrm{C}}$ glycosylation directly or indirectly via interactions with cellular cofactors plays a role in maintenance of strain properties during prion conversion (18). The small differences in incubation period between WT and Prnp ${ }^{180 Q / 196 Q}$ mice infected with RML suggest that glycosylation may not substantially affect prion formation in contrast to what has been observed in vitro where glycosylation inhibits prion formation (19, 20). Several scenarios could explain this discrepancy. It is possible that the strains tested in this study respond differently to changes in glycosylation compared with strains that were used in the in vitro studies $(13,19,20)$. Many factors in addition to the kinetics of $\mathrm{PrP}^{\mathrm{Sc}}$ accumulation can influ- ence the incubation period of disease. The relative rate of $\mathrm{PrP}^{\mathrm{sc}}$ formation, clearance, and transport to populations of neurons that are susceptible to $\operatorname{PrP}^{\mathrm{Sc}}$ neurotoxicity are only a few of the factors that contribute to the incubation period of disease.

When Sevillano and colleagues introduced a third glycosylation site in $\mathrm{PrP}^{\mathrm{C}}$, the incubation period shortened. Further, there was a corresponding increase in diffuse $\mathrm{PrP}^{\mathrm{Sc}}$ aggregates and an absence of $\mathrm{PrP}^{\mathrm{Sc}}$ plaques (13). These findings suggest that a more rapid disease course corresponds with diffuse $\mathrm{PrP}^{\mathrm{sc}}$ deposits. While more work is needed to further characterize the contributions of posttranslational modifications of $\operatorname{PrP}^{\mathrm{C}}$ and the prion strain to prion pathogenesis, the Sevillano et al. study illustrates that shifting diffuse synaptic $\mathrm{PrP}^{\mathrm{Sc}}$ deposits to plaques is a viable therapeutic modality to slow the progression of prion disease.

\section{Acknowledgments}

JCB is supported by the National Institute of Allergy and Infectious Diseases and the National Institute of Neurological Disorders and Stroke of the NIH via grants P01 0011877A, R01 NS103763, and R01 NS107246, and by award CWD20-018 from the State of Michigan.

Address correspondence to: Jason C. Bartz, Department of Medical Microbiology and Immunology, 2500 California Plaza, Omaha, Nebraska 68178, USA. Phone: 402.280.1811; Email: jbartz@ creighton.edu.

1. Deleault NR, Harris BT, Rees JR, Supattapone S. Formation of native prions from minimal components in vitro. Proc Natl Acad Sci USA. 2007;104(23):9741-9746.

2. Prusiner SB. Novel proteinaceous infectious particles cause scrapie. Science. 1982;216(4542):136-144.

3. Bessen RA, Marsh RF. Distinct PrP properties suggest the molecular basis of strain variation in transmissible mink encephalopathy. J Virol. 1994;68(12):7859-7868.

4. Fraser H, Dickinson AG. Distribution of experimentally induced scrapie lesions in the brain. Nature.1967;216(5122):1310-1311.
5. Bruce ME, Dickinson AG. Biological stability of different classes of scrapie agent. In: Prusiner SB, Hadlow WJ, eds. Slow transmissible diseases of the nervous system. Vol 2. New York, New York, USA: Academic Press; 1979:71-86.

6. Stahl N, Borchelt DR, Hsiao K, Prusiner SB. Scrapie prion protein contains a phosphatidylinositol glycolipid. Cell. 1987;51(2):229-240.

7. Chesebro B, et al. Anchorless prion protein results in infectious amyloid disease without clinical scrapie. Science. 2005;308(5727):1435-1439.

8. Endo T, Groth D, Prusiner SB, Kobata A. Diversity of oligosaccharide structures linked to asparagines of the scrapie prion protein. Biochemistry. 1989;28(21):8380-8388.

9. Oesch B, et al. A cellular gene encodes scrapie PrP 27-30 protein. Cell. 1985;40(4):735-746.

10. Tuzi NL, et al. Host PrP glycosylation: a major factor determining the outcome of prion infection. PLoS Biol. 2008;6(4):e100.

11. Bett C, et al. Enhanced neuroinvasion by smaller, soluble prions. Acta Neuropathol Commun. 2017;5(1):32.

12. Cancellotti E, et al. Glycosylation of PrPC deter mines timing of neuroinvasion and targeting in the brain following transmissible spongiform encephalopathy infection by a peripheral route. J Virol. 2010;84(7):3464-3475.

13. Sevillano, et al. Prion protein glycans reduce intracerebral fibril formation and spongiosis in prion disease. J Clin Invest. 2020;130(3):1350-1362.

14. Linsenmeier L, et al. Structural and mechanistic aspects influencing the ADAM10-mediated shedding of the prion protein. Mol Neurodegener. 2018;13(1):18.

15. Katorcha E, Makarava N, Savtchenko R, D’Azzo A, Baskakov IV. Sialylation of prion protein controls the rate of prion amplification, the cross-species barrier, the ratio of PrPSc glycoform and prion infectivity. PLoS Pathog. 2014;10(9):e1004366.

16. Shikiya RA, et al. PrPSc formation and clearance as determinants of prion tropism. PLoS Pathog. 2017;13(3):e1006298.

17. Piro JR, et al. Prion protein glycosylation is not required for strain-specific neurotropism. J Virol. 2009;83(11):5321-5328.

18. Deleault NR, et al. Cofactor molecules maintain infectious conformation and restrict strain properties in purified prions. Proc Natl Acad Sci USA 2012;109(28):E1938-E1946.

19. Camacho MV, Telling G, Kong Q, Gambetti P, Notari S. Role of prion protein glycosylation in replication of human prions by protein misfolding cyclic amplification. Lab Invest. 2019;99(11):1741-1748.

20. Makarava N, Savtchenko R, Baskakov IV. Selective amplification of classical and atypical prions using modified protein misfolding cyclic amplification. J Biol Chem. 2013;288(1):33-41. 